\title{
Narrative Exposure Therapy for the integration of migrants with PTSD in the light of MIPEX integration project in Europe
}

\author{
Terapia de Exposição Narrativa para a integração de migrantes \\ com Disfunção por Stress Pós-Traumático à luz do Projeto de \\ Integração do MIPEX na Europa
}

Aqsa Khalid ${ }^{1}$

\begin{abstract}
People who migrate in uncertain and traumatic circumstances can suffer from symptoms of Post-Traumatic Stress Disorder (PTSD). The life they will live after traumatic events can affect the process of treatment and healing. Daily stressors in host communities including basic survival needs, insecure and unhygienic shelter, lack of social support, language and cultural barriers, low socioeconomic status, and job insecurity can affect the process of integration negatively. This paper will explore the literature to understand the effects of short-term Narrative Exposure Therapy (NET) along with the role of Migrant Integration Policy Index (MIPEX) tool on the integration of migrants suffering from PTSD. Literature supports that NET is effective as it has shown to help reduce the symptoms of PTSD in migrants, but social factors and daily stressors can become a hindrance in treatment. Some MIPEX tool indicators address the daily stressors which are required to decrease the symptoms of PTSD. Therefore, research concludes that NET and some MIPEX tool indicators if implemented correctly and simultaneously can help in reducing symptoms of PTSD and eventually help migrants better integrated.
\end{abstract}

Keywords: Post-Traumatic Stress Disorder, Integration, Narrative Exposure Therapy, Migrant Integration Policy Index, Mental Health.

Resumo: Pessoas que migram em circunstâncias incertas e traumáticas podem sofrer de sintomas de Transtorno de Estresse Pós-Traumático (TEPT). A vida após eventos traumáticos pode afetar o processo de tratamento e cura. Situações diárias de estresse nas localidades anfitriãs, tais como necessidades básicas de sobrevivência, moradia insegura e insalubre, falta de apoio social, barreiras linguísticas e culturais, baixo status socioeconômico e desemprego podem afetar negativamente o processo de integração. Em vista disso, este artigo explorará a literatura existente para entender os efeitos da Terapia de Exposição Narrativa (NET, em inglês) de curto prazo, ao lado dos dados obtidos a partir do Índice de Políticas de Integração de Migrantes (MIPEX, em inglês) na integração de migrantes que sofrem de TEPT. A literatura expõe que a

\footnotetext{
${ }^{1}$ Master in Clinical Social Work from the Baskent University Ankara - Turkey. Masters in Arts candidate of the European Masters of Migration and Intercultural Relations (EMMIR) at the University of Oldenburg - Germany, and the University of Witwatersrand - South Africa. Bachelor in Psychology from GC University Lahore - Pakistan. Intern at the IOM-UN Migration Health Unit in Brussels.
} 
NET é eficaz, demonstrando ajudar a reduzir os sintomas de TEPT em migrantes, apesar de fatores sociais e situações diárias de estresse poderem se tornar obstáculos no tratamento. Alguns indicadores da ferramenta MIPEX abordam as situações diárias de estresse necessários como forma de diminuir os sintomas do TEPT. Portanto, a pesquisa conclui que a NET e alguns indicadores da ferramenta MIPEX, se implementados corretamente e simultaneamente, podem ajudar a reduzir os sintomas do TEPT e, eventualmente, ajudar os migrantes a se integrarem melhor nas localidades anfitriãs.

Palavras-chave: Transtorno de Estresse Pós-Traumático, Integração, Terapia de Exposição Narrativa, Índice de Políticas de Integração de Migrantes, Saúde Mental.

\section{Introduction}

World Health Organization has recently included mental health and well-being in UN sustainable development goals (2019). Decades of disasters and the outbreak of conflicts have resulted in devastating effects on civilians. Loss and grief sometimes become overwhelming and victims may find it very difficult to communicate the emotions and perceptions related to trauma (Schauer and Schauer 2010). The burden of disease is increasing particularly in places with scarce resources and with a vulnerable population. Research initiatives should be focused to understand the causes (Albarqouni, Elessi, et al. 2018).

The term "Trauma" comes from Greek and it means "injury or wound" (Schauer, Neuner, et al. 2011). Post-traumatic stress disorder (PTSD) is a clinical mental disorder that needs to be treated for normal functioning in life. (2013). Psychological trauma can be experienced after a life-threatening or shocking event with the danger of injury to oneself or someone else. A person can experience psychophysiological symptoms, helplessness and can feel horrified during and after the traumatic events (Schauer, Neuner, et al. 2011). Life after the traumatic events can affect how the person would grow and heal. Trauma victims who migrate internally or by crossing borders might face daily stressors in a new place including basic needs such as clean drinking water, insecure residential status, social problems including less 
social support, language barriers, education for children, cultural differences, low social and economic status and most importantly fewer job opportunities (Budosan, Aziz, et al. 2016). These daily stressors if continue, would negatively influence the integration of migrants.

Efforts to integrate should not be the responsibility only of immigrants. European shared approach for immigrant integration referred to as Common Basic Principles (CBP) defines integration as "A dynamic, two-way process of mutual accommodation by all immigrants and residents of Member States"(Garcés-Mascareñas and Penninx 2016). The recent shift to look at integration as a three-way approach which includes the country of origin too is still debated and researched (Garcés-Mascareñas and Penninx 2016). But what kind of accommodation is and what issues include in the process of integration? Migration Integration Policy Index is a tool to measure integration policies in 38 countries. It focuses on 8 policy areas and 167 indicators as a subset of those policies at work and it is very useful to measure and compare policies in different countries (MIPEX 2015). So, why integration and better adjustment is important? On research says that better living conditions can help improve the mental health of refugees and internally displaced people even more than psychological and psychiatric interventions (Hassan, Ventevogel, Jefee-Bahloul, \& Barkil-Oteo, 2016).

Narrative Exposure Therapy NET is one of those treatments for PTSD in a vulnerable population, which has proven to be effective. It is short-term hence it is practical to be used with vulnerable people like migrants who are mostly on the move (Schauer M., Schauer, Neuner, \& Thomas, 2011). Narrative exposure therapy (NET) is used to treat PTSD in survivors of war, torture, domestic violence or any other disaster. It is a standardized short-term treatment (Crombach \& Siehl, 2018). Various Randomized controlled trials have shown the positive effect of NET on victims' multiple traumatic events who suffer from PTSD (ibid.) Countries with post-conflict and post-disaster circumstances usually have fewer 
resources and time to treat patients with long term treatments. It is also more valuable and practical because it has proved to be useful in a shortterm form (4-8 sessions) (Crombach \& Siehl, 2018)

This paper will follow an exploratory research method to understand the relationship between integration difficulties such as daily stressors and trauma, and the effects of NET on aspects related to the integration of migrants with PTSD. The present paper will also use the Migrant Integration Policy Index (MIPEX) project as a guiding tool to measure integration, which follows the highest European and international standards to facilitate and understand immigrant integration (MIPEX 2015).

\section{Theoretical Perspective}

Social theory is of the view that over-diagnosis and pathologizing of emotions are harmful to people with PTSD. This perspective claims that emotions are relative to different cultures and social situations. The reasons behind PTSD are not only psychiatric ones but also sociopolitical ones. People experience various problems after each or multiple traumatic events. Research accepts that social factors are very central in the growth and maintenance of PTSD later. How an individual respond to traumatic events can also depend on social factors around him. Social factors can include community function and support, daily support, displacement, disconnection, living conditions, material loss, loss of role, food, finance, disorganized services, employment, leisure activities (Bisson, 2000). If we can focus on improving social factors after a person is displaced, the response to previous or current traumatic events can be changed. Symptoms can not only be treated by dealing with imbalanced neurotransmitters or by correcting irrational thought patterns but at the same time addressing social factors are crucial, otherwise symptoms of PTSD might preserve. Poor 
social support and social factors can lead to the development and maintenance of PTSD symptoms. This can imply that if a person is not integrated, the chances of continuation or aggravation of PTSD symptoms are high.

Individual vulnerability in a certain situation has a role to play in how a person would react to trauma. The intensity of exposure is not enough to understand this. The severity of the trauma, lack of social support after it and life stresses that would follow would make the strongest combination for the risk of PTSD. Pre-trauma factors were weaker than these during and port-trauma factors according to this research (Brewin, Andrews, \& Valentine, 2000). It becomes a vicious cycle of impairment in health and a negative economy and devastating mental health (Dan Chisholm, et al., 2016). Human misery can continue if it is studied by focusing only on one dimension.

\section{State of Research}

Treatment for trauma should not be delayed until refugees settle in a permanent place. Research done in 2013 supports the claim that treatment for trauma should start as soon as possible (Stenmark, Catani, Neuner, Elbert, \& Holen, 2013). Torture victims in a new place can face different challenges including legal, financial and social problems. The new place may not always be safe, and the threat of deportation is constant stress. Stressful social and material conditions play a very important role in mental health after war exposure, which is sometimes ignored by mental health professionals (Miller \& Andrew, 2010).

Research done in 2017 about the Arab and African region with torture survivors is a good example of evidence-based research (Hansen, Nete, Smeir, Engelkes Heby, \& Modvig, 2017) Narrative Exposure Therapy NET is effective in decreasing the symptoms of PTSD in adults when 
assessed in randomized controlled trials (RCTs) and is a successful psychosocial intervention. If the client and therapist share the same language and understanding of cultural norms, it positively affects the NET treatment for PTSD symptoms. After four month's follow-up, study participants reported that they are better integrated into the society, which was shown by questions related to increased participation in society, feeling of having a role in their lives, fewer problems with sleeping and less fear in their heart, communication, and relationships with others have improved (Hansen, Nete, Smeir, Engelkes Heby, \& Modvig, 2017).

This study also supports the previous studies' result that daily stressors affect the effect of Narrative Behavior therapy on the symptoms of PTSD (Miller \& Andrew, 2010). Therapies sometimes go on for weeks and months. Migrants are early periods of migration that might not have a permanent or long-term place to live. A lot of them must drop out of sessions because they forcefully or voluntarily must move because of several reasons including feelings of threat or a new job (Hansen, Nete, Smeir, Engelkes Heby, \& Modvig, 2017).

Risk of developing mental health disorder includes the lifethreatening nature of the disaster, irreversible physical impairment, loss of materials and loved ones. An extensive review shows that even if the victims get the relief efforts by the host community in form of material aid, it will be hard for them to use the help and benefits effectively and fully if they are not recovered (Galea, Nand, \& Vlahov, 2005). Experts say that reducing daily stress like financial problems and settlement issues should be dealt with using psychosocial interventions to address mental health issues in such situations (Miller KE \& A., 2010).

Research done with former child soldiers suggested that symptoms of PTSD are associated with "A reduced openness to reconciliation and elevated feelings of revenge". Therefore, if they are not integrated into a community, the feelings of trust and collaboration might persist (Bayer, 
Klasen, \& Adam, 2007). Daily stressors can also be perceived differently or exaggerated by people suffering from mental health issues. Traumatized people might feel threatened easily. Clinicians ask now to treat traumarelated disorder using a context-specific treatment (Weiss MG1, 2011).

\section{Research Methodology}

The present study has as its main objective discover whether Narrative Exposure Therapy NET helps in the process of integration by treating and reducing the symptoms of PTSD in migrants. The present study will also find out if the MIPEX tool addresses the daily stressors which contribute to symptoms of PTSD in the post-settlement process.

For that matter, it will use a qualitative approach and exploratory research method by doing a review of the literature and analysis of data. It is a method that approaches data with a flexible mind and tries to understand and investigate relevant information and make sense of messy human phenomena (Yu, 2017). It would be like an initial research perspective which could be a basis of further researches. As a part of data, a review of the literature was done using electronic and print resources including websites, academic journals, and books.

In regard to data analysis, it has been done by describing and then correlating patterns like daily stressors with integration problems. The effect of NET on PTSD survivors have been linked with facilitation in the process of integration by reviewing the literature.

\section{Overview of the Material}

\subsection{Migrant Integration Policy Index - MIPEX}

The Migrant Integration Policy Index (MIPEX) is an online index that is a tool to analyze and measure policies to integrate migrants. It is mainly 
run by the Barcelona Centre for International Affairs (CIDOB) and Migration Policy Group (MPG) in cooperation with organizations from 38 countries which are part of this project. It believes in equal opportunities, equal rights, dignified, independent and active lives and having mutual rights based on equality for all migrants. Their target groups are advocacy, government, global actors and research press. It has 8 policy areas and 167 indicators to understand the multiple factors that influence the integration of migrants into society. It helps to understand and asses the changes in policies and furthermore new policies and proposals for change can be based on the data and analysis. Scores are given to each country in each policy area by experts and peer reviewers. (MIPEX, 2015). The present study will use MIPEX policy indicators and a tool to understand and measure integration aspects.

\subsection{Narrative Exposure Therapy}

Narrative Exposure therapy is a standardized therapy to treat trauma and reduce symptoms related to PTSD. It is based on the principles of cognitive-behavioral exposure and testimony therapy. The patient is asked to repeatedly recall and talk about the experience that was faced but in detail in the exposure therapy stage. During treatment, the re-experience of all emotions, bodily sensations and memory related to the event are stressed but the client is assisted by the therapist to keep in mind the time and space. (Schauer M., Schauer, Neuner, \& Thomas, 2011, p. 34). This helps them to realize the difference between the past traumatic event and current contradictory reality. It helps in reducing the symptoms of trauma. Testimony therapy includes biographical narration and writing of a document about life events with the collaboration of client and therapist. It becomes a valuable resource for them to speak up their minds, express their miseries and ask for rights. "NET is being used and possible to be effective 
in different cultures. It involves story writing and listening to narrative which is a tradition if many cultures". (Hansen, Nete, Smeir, Engelkes Heby, \& Modvig, 2017).

NET follows some general organizations of sessions (4-8) and one session can last from 90 to 120 minutes. A general guideline for all sessions can include discussion about diagnosis, psychoeducation, lifeline, the start of the narration from beginning till the first traumatic event, narration about subsequent life events and next traumatic events, rereading and singing of the whole document. (Schauer M., Schauer, Neuner, \& Thomas, 2011, p. $38)$.

\section{Detailed Analysis}

\subsection{NET Individual/Community Level Goal and Integration}

Mental health services for trauma victims are rare in poor countries affected by conflicts and disasters Narrative Exposure therapy affects both individual victims and society. (Schauer \& Schauer, 2010). People with mental health disorders and extreme stress cannot focus on daily social and economic activities which are important for the healthy survival of themselves and their families. Nightmares, constant flashbacks can affect their daily mobility and they can feel they are out of control and not worthy like others. Not being able to perform their social duties and roles can result in a lack of ability to earn like others, lack of hope and even suicidal ideations.

Studies have shown the efficacy of trauma treatment methods which can be applied by trained local counselors. Healing from these treatments can reduce an individual's emotional pain which as a result assist the person to be productive. It decreases the level of violence by reducing the level of feelings of aggression in the person with trauma. (Schauer \& Schauer, 2010). Narrative Exposure Therapy (NET) is a treatment specially 
designed for survivors of violence and torture with Post-traumatic stress disorder PTSD and evidence-based research supports it. (McPherson, 2012). After NET treatment, people can involve themselves in social relationships as before, they can start their work and fieldwork again. This not only affects the individual, but it also leads to the development of community and economy (Schauer M., Schauer, Neuner, \& Thomas, 2011, p. $5)$.

Migrants if faced with traumatic events are usually victims of not one but multiple traumas. The treatments for one traumatic event and a person who has faced multiple traumas would differ and NET has been recommended for that according to a systematic review. (Crumlish \& O'Rourke, 2010). NET has received evidence-based support for treating symptoms of PTSD in survivors of violence and conflict and it is better than only psychoeducation. (Mørkved, et al., 2014). Testimony therapy process promotes healing by giving a purpose or meaning to individuals, who were hopeless before. It gives them a chance to speak for their rights and miseries. "Testimonies enhance psychosocial functioning in terms of (1) documenting and communicating the story; (2) reconstructing a sense of self, identity, and attachment to the community". (Mørkved, et al., 2014)

Research shows a statistically significant reduction in symptoms of Posttraumatic stress disorder in people who had survived torture and received NET. (Hansen, Nete, Smeir, Engelkes Heby, \& Modvig, 2017). NET might also help in reducing daily stressors related to stigmatizing because of PTSD. (Crombach \& Siehl, 2018).

\subsection{NET Political Level Goal and Integration}

NET has another goal which is different from individual healing and community development. Testimonies are written after the writing of a biographical story by the client and therapist. With the consent of the client/patient, the document could be forwarded to human rights 
organizations. It can be a very useful recourse and document to teach about the past, learn about the present and prepare for the future.

These testimonies can be passed to the public, researchers, and educators. They can be used for advocacy but by keeping the safety and anonymity of the client into consideration. (Schauer M., Schauer, Neuner, \& Thomas, 2011). This political purpose of NET can serve to raise voice against human rights violations in press, media, and parliaments, etc. It might help people get their rights like help to get employment, health security, resources for food and housing, family reunification, which are very important for rehabilitation. It will eventually help in their integration in the host society.

\subsection{Social, Economic and Helath-related aspects related to Integration}

\subsubsection{Social}

If a person is suffering from trauma, he/she might not be able to function properly in a social and economic context, and it can lead them to feel inferior. Results of therapy can be affected by the social status and social identity of the client in that place for example asylum or refugee status. (Hansen, Nete, Smeir, Engelkes Heby, \& Modvig, 2017). Daily stressors of a refugee or asylum seekers with PTSD may include lack of community function and social support, lack of social ties and connections, loss of role, lack of family presence and its support, disorganized services provided by the host community, lack of leisure activities, etc. If a person with PTSD has perceived poor social support including all or some of the daily stressors mentioned above, it can be associated with the condition of PTSD symptoms. (Bisson, 2000).

Another aspect is about culturally sensitive therapists and counselors. A therapist who is sensitive towards the socio-cultural 
background of the client is going to be more effective for the therapeutic relationship and overall treatment. Local experts should be involved in the screenings and treatment process. (Schauer \& Schauer, 2010). These aspects are related to the social adjustment of people with PTSD and integration as well.

\subsubsection{Health}

One important policy area of integration is related to the health of migrants. A study also shows that somatic symptoms of a person with PTSD can improve with NET sessions. Self-reported health and pain perceptions were improved in participants. There shows a positive association between psychological health and somatic health which can be improved with NET. (Hansen, Nete, Smeir, Engelkes Heby, \& Modvig, 2017).

\subsubsection{Economic}

The mental health of refugees can be improved with better living conditions (G, Ventevogel, Jefee-Bahloul, Barkil-Oteo, \& Kirmayer, 2016). A researcher was done with refugees and it showed after 4-months follow up that people felt stressful because of lack of food rations. This led to an increase in symptoms of negative mental health (Neuner, Schauer, Klaschik, Karunakara, \& Elbert, 2004). Stigmatization is also a big problem in the way of psychological treatment provision.

The circumstances in crowded places mean there is less privacy given to someone who is taking part in psychological intervention. Lack of resources and competition for resources also pose a threat to the presence of psychological intervention (Crombach \& Siehl, 2018). Displacement, bad living conditions, loss of material things and memories, financial constraints and no job are one of those big stressors that can aggravate or associate with symptoms of PTSD (Bisson, 2000). 


\section{Overarching Analysis}

\subsection{Analysis of MIPEX integration policies and corresponding daily stressors}

Daily stressors can affect the process of integration of asylum seekers and refugees if they have PTSD. If migrants are not integrated and they persistently face daily stressors, it can affect the effect of NET on PTSD symptoms (Hansen, Nete, Smeir, Engelkes Heby, \& Modvig, 2017). According to Bisson (2000), PTSD is also a product of sociopolitical reasons and not only for psychiatric reasons. Mental health can be influenced by daily stressors which can include language barrier, differences of culture, low employment rates and low social status, poor living conditions and lack of social support and stability (Hansen, Nete, Smeir, Engelkes Heby, \& Modvig, 2017). Some daily stressors which could become a hindrance in the integration of migrants can reduce by addressing mental health issues (Crombach \& Siehl, 2018).

Research also says that if a person experience stress repeatedly. "It will enlarge and reinforce the fear drama structure while disconnecting its elements from the contextual cues when and where the traumatic stress are has been experienced at the same time this will lead to the development of chronic post-traumatic stress disorder" (Schauer M., Schauer, Neuner, \& Thomas, 2011).

The table below shows the daily stressors that can lead to the maintenance and aggravation of PTSD showed by the review of the literature and detailed analysis and on the other hand is corresponding MIPEX policy indicators of integration. Most of the daily stressors that can be a problem for symptoms of PTSD has a corresponding policy indicator in MIPEX other than lack of any leisure activity. In short, integration policy indicators if implemented can help in reducing symptoms of PTSD. 
Table 1 - Daily stressors leading to PTSD and corresponding MIPEX policy indicators

\begin{tabular}{|l|l|}
\hline \multicolumn{1}{|c|}{ Daily Stressors leading to PTSD } & MIPEX policy indicators of Integration \\
\hline Language barrier & Interpretation Facilities \\
\hline Difference of culture & Provision of 'cultural mediators \\
\hline Low social status & $\begin{array}{l}\text { Access to education, labor market, housing } \\
\text { conditions etc. }\end{array}$ \\
\hline Instability & $\begin{array}{l}\text { Stability: access to services of permanent } \\
\text { residence, general support for employment, } \\
\text { worker's rights, education, and housing, etc. }\end{array}$ \\
\hline Low Employment Rates & Support for and access to the labor market \\
\hline Poor living conditions & $\begin{array}{l}\text { Access to housing, social security, and } \\
\text { assistance }\end{array}$ \\
\hline Lack of social support and social ties & $\begin{array}{l}\text { Family reunification rules, social life in } \\
\text { educational and vocational institutions }\end{array}$ \\
\hline Disorganized services by host communities & $\begin{array}{l}\text { Responsive services related to employment, } \\
\text { health, education, housing, legal status, etc. }\end{array}$ \\
\hline Absence of family & Family reunification policy \\
\hline Lack of leisure activities & NIL \\
\hline Competition for resources & $\begin{array}{l}\text { Worker's rights, access to services related to } \\
\text { education, health, labor market, housing, } \\
\text { etc. }\end{array}$ \\
\hline
\end{tabular}

Source: elaborated by the author

\subsection{Effects of NET on Trauma Victims and MIPEX Integration Policy aspects}

MIPEX tool index measures and understand the concept of integration using different policy areas and dimensions. One important policy for integration is to provide opportunities like national to have access to jobs and improve their skills by access to the labor market, selfemployment, support to have access to employment services and housing. It also considers access to education an important part of the integration.

Segregation of migrant pupils is supposed to be countered to promote integration. Diversity in school life is encouraged and support for migrant parents and communities is expected to enable them to be integrated. It considers reunited families as an important aspect of integration. Legal protection and support for families for employment and housing are considered an important aspect of integration. If health services are provided with 'cultural mediators' or diversity sensitive services to facilitate 
access for migrants, it will help in the integration. Interpretation services should be present.

Participation and opportunities for legally resided foreign citizens in political life just like nationals are considered a sign of integration. Integration also means that migrants are not discriminated based on their social and legal status, race, ethnicity, etc. They should have access to public goods and services including health. There should be a system made to assist and protect victims of discrimination. Public bodies are obliged to have a system that protects migrants against victimization and promotes equality.

Daily stressors, the effect of NET treatment and resulting integration and integration efforts, all are interrelated. The efficacy of NET treatment shows that the person not only improves the PTSD symptoms but at the same time the resulting behavior corresponds to the integration aspects.

Table 2 - Effects of NET on Trauma Victims and corresponding MIPEX Integration policy indicators

\begin{tabular}{|c|c|}
\hline Effects of NET on Trauma Victims & MIPEX Integration Policy Indicators \\
\hline The daily stress of stigmatization is lowered & $\begin{array}{l}\text { Protection for migrants } \\
\text { victimization }\end{array}$ \\
\hline Being able to work or get employed & $\begin{array}{l}\text { Support for and access to the labor } \\
\text { market }\end{array}$ \\
\hline Social relationships back to normal & Family reunification policies \\
\hline Being productive & Education and vocational training \\
\hline Testimonies to have a voice in political arena & Participate in political life \\
\hline Testimonies to ask for and get rights & Participation in political liberties \\
\hline Culturally competent therapists are beneficial & Provision of 'cultural mediators' \\
\hline Social Status and improvement in trauma & $\begin{array}{l}\text { Access to social security, housing } \\
\text { conditions, rights to apply for permanent } \\
\text { residence, etc. }\end{array}$ \\
\hline Social Identity after improvement in trauma & Laws against discrimination \\
\hline $\begin{array}{l}\text { Improvement in Self-reported health and pain } \\
\text { perceptions }\end{array}$ & $\begin{array}{l}\text { Health entitlement for migrants, and } \\
\text { polices to facilitate access to health } \\
\text { services }\end{array}$ \\
\hline Improved living conditions & $\begin{array}{l}\text { Access to and supply of public goods and } \\
\text { services, including housing }\end{array}$ \\
\hline Lack of extreme financial constraints & $\begin{array}{l}\text { Economic integration measures, access to } \\
\text { general support for employment, worker's } \\
\text { rights, Study grants, etc. }\end{array}$ \\
\hline
\end{tabular}

Source: elaborated by the author 
It can be seen from Table 2 that the effects of NET on trauma victims have a corresponding policy planned for integration in MIPEX. This implies that Narrative Exposure Therapy helps in different aspects of the integration of migrants who survived violence and traumatic events and suffer from PTSD. This could also mean that better integration and reduced PTSD are a result of both the treatment and efforts for integration and not just treatment exclusively.

\section{Conclusion}

The present paper has shed light on the issue of the integration of migrants who suffer from PTSD. Daily stressors are a big hindrance in the process of integration, and they can diminish or reduce the effect of therapy. A review of the literature has shown that the effects of NET are positive for migrants suffering from PTSD after each or multiple traumatic events. NET also helps in the integration of clients by reducing daily stressors. Integration policy indicators such as shown in the MIPEX tool also gives importance to address and improve the same daily stressors which are very important for the mental health of migrants in post-settlement processes. In conclusion, NET and integration policy indicators which are shown in MIPEX if implemented successfully and simultaneously can help in reducing symptoms of PTSD in vulnerable migrants and eventually help them better integrated.

Nonetheless, more research should investigate the evidence-based research on the combination of both treatment and external help for the integration of people suffering from PTSD. The present research used the MIPEX tool as an indication of integration. Research is needed that measures subjective interpretation of participants about their own understanding of integration. 


\section{References}

ALBARQOUNI, L., ELESSI, K., \& ABU-RMEILEH, N. The relation between health research output and burden of disease in Palestine: a systematic review. The Lancet, 2018.

AMERICAN PSYCHIATRIC ASSOCIATION. Diagnostic And Statistical Manual Of Mental Disorders. Washington, DC, 2013.

BAYER, C., KLASEN, F., \& ADAM, H. Association of trauma and PTSD symptoms with openness to reconciliation and feelings of revenge among former Ugandan and Congolese child soldiers. JAMA, pp. 555-559, 2007.

BISSON, J. Psychological and social theories of post-traumatic stress disorder. Psychiatry, 290-292, 2000.

BREWIN, C. R., ANDREWS, B., \& VALENTINE, J. D. Meta-Analysis of Risk Factors for Posttraumatic Stress Disorder in Trauma-Exposed Adults. Journal of Consulting and Clinical Psychology, pp. 748-766, 2000.

BUDOSAN, B., AZIZ, S., BENNER, M., \& ABRAS, B. Perceived needs and daily stressors in an urban refugee setting: Humanitarian Emergency Settings Percieved Needs Scale of Syrian refugees. Intervention, pp. 1-12, 2016.

CROMBACH, A., \& SIEHL, S. Impact and cultural acceptance of the Narrative Exposure Therapy in the aftermath of a natural disaster in Burundi. BMC Psychiatry, pp. 1-15, 2018.

CRUMLISH, N., \& O'ROURKE, K. A systematic review of treatments for posttraumatic stress disorder among refugees and asylum-seekers. The journal of Nervous and Mental Disease, pp. 237-251, 2010.

CHISHOLM, D.; SWEENY, K.; SHEEHAN, P.; RASMUSSEN, B.; SMIT, F.; CUIJPERS, P. \& SAXENA, S. Scaling-up treatment of depression and anxiety: a global return on investment analysis. Lancet Psychiatry, pp. 415-424, 2016.

G, H., V. P., J.-B. H., B.-O. A., \& K. L. Mental health and psychosocial wellbeing of Syrians affected by armed conflict. Epidemiology and Psychiatric Sciences, pp. 129-141, 2016.

GALEA, S., NAND, A., \& VLAHOV, D. The epidemiology of post-traumatic stress disorders after disastor. Epidemiological Review, pp. 78-91, 2005.

GARCÉS-MASCAREÑAS, B., \& PENNINX, R. Introduction: Integration as a Three-Way Process Approach? In R. Penninx, \& B. Garcés-Mascareñas, Integration Processes and Policies in Europe. Springer, 2016.

HANSEN, A. K., N. S.-N., SMEIR, I., ENGELKES HEBY, L., \& MODVIG, J. Impact of Narrative Exposure Therapy on torture survivors in the MENA region. Torture, pp. 49-63, 2017.

HASSAN, G., VENTEVOGEL, P., JEFEE-BAHLOUL, H., \& BARKIL-OTEO, A. Mental health and psychosocial wellbeing of Syrians affected by armed conflict. Epidemiology and Psychiatric Sciences , pp. 129-141, 2016.

MAUTHNER, N. S., \& \& DOUCET, A. Reflexive Accounts and Accounts of Reflexivity in Qualitative Data Analysis. Sociology, pp. 413-431, 2003.

MCPHERSON, J. Does Narrative Exposure Therapy Reduce PTSD in Survivors of Mass Violence? Research on Social Work Practice, pp. 29-42, 2012. 
Miller KE, \& A., R. War exposure, daily stressors, and mental health in conflict and postconflict settings: bridging the divide between trauma focused and psychosocial frameworks. Social Science and Medicine, pp. 7-16, 2010.

MILLER, K. E., \& A. R. War exposure, daily stressors, and mental health in conflict and post-conflict settings: Bridging the divide between trauma-focused and psychosocial frameworks. Social Science and Medicine, pp. 7-16, 2010.

MIPEX. Migrant Integration Policy Index (MIPEX). 2015. Available at: $<$ http://mipex.eu/>. Accessed on oct. 2019.

MØRKVED, N., K. H., L.M. AARSHEIMA, D. HOLENA, A.M. MILDE, J. B., \& S. T. A comparison of Narrative Exposure Therapy and Prolonged Exposure therapy for PTSD. Clinical Psychology Review , pp. 453-467, 2014.

NEUNER, F., SCHAUER, M., KLASCHIK, C., KARUNAKARA, U., \& ELBERT, T. A Comparison of Narrative Exposure Therapy, Supportive Counseling, and Psychoeducation for Treating Posttraumatic Stress Disorder in an African Refugee Settlement. Journal of Consulting and Clinical Psychology, pp. 579-587, 2004.

SCHAUER, M., \& SCHAUER, E. Trauma-Focused Public Mental-Health Interventions: A Paradigm Shift in Humanitarian Assistance and Aid Work. Trauma rehabilitation after war and conflict: Community and individual perspectives, pp. 389-428, 2010.

SCHAUER, M., NEUNER, F., \& ELBERT, T. Traumatic Stress. In: M. Schauer, F. Neuner, \& T. Elbert, Narrative Exposure Therapy: A Short-Term Treatment for Traumatic Stress Disorders. Gottingen: Hogrefe Publishing, 2011.

SCHAUER, M., SCHAUER, M., NEUNER, F., \& THOMAS, E. Narrative Exposure Therapy: A Short-Term Treatment for Traumatic Stress Disorders. Gottingen: Hogrefe Publishing, 2011.

STENMARK, H., CATANI, C., NEUNER, F., ELBERT, T., \& HOLEN, A. Treating PTSD in refugees and asylum seekers within the general health care system. A randomized controlled multicenter study. Behvaior Research and Therapy, pp. 641-647, 2013.

WEISS, S. B. Mental health in the aftermath of disasters: consensus and controversy. The journal of nervous and mental disease, pp. 611-615, 2011.

WHO. Mental health included in the UN Sustainable Development Goals. Geneva, 2019. Available at: <https://www.who.int/mental_health/SDGs/en/>. Accessed on Mar. 2019.

YU, C. H. Exploratory Data Analysis. Nov. 29, 2017.

Artigo recebido em: 04/09/2019.

Aceito para publicação em: 19/11/2019. 